\title{
The Impact of Universal Mask Use on SARS-COV-2 in Victoria, Australia on the Epidemic Trajectory of COVID-19
}

\author{
Valentina Costantino ${ }^{1 *}$ and Chandini Raina Maclntyre ${ }^{1,2,3}$ \\ ${ }^{1}$ The Biosecurity Program, The Kirby Institute, University of New South Wales, Kensington, NSW, Australia, ${ }^{2}$ College of \\ Health Solutions, Arizona State University, Tempe, AZ, United States, ${ }^{3}$ College of Public Affairs and Community Solutions, \\ Arizona State University, Tempe, AZ, United States
}

OPEN ACCESS

Edited by:

Zisis Kozlakidis,

International Agency for Research on

Cancer (IARC), France

Reviewed by:

Si Man Lei,

University of Macau, China

Kimberlyn Roosa,

The University of Tennessee, Knoxville,

United States

*Correspondence:

Valentina Costantino

vale.cost@protonmail.com

Specialty section: This article was submitted to Infectious Diseases - Surveillance,

Prevention and Treatment,

a section of the journal

Frontiers in Public Health

Received: 03 November 2020

Accepted: 10 March 2021

Published: 21 April 2021

Citation:

Costantino $V$ and Raina Maclntyre $C$ (2021) The Impact of Universal Mask

Use on SARS-COV-2 in Victoria, Australia on the Epidemic Trajectory of

COVID-19.

Front. Public Health 9:625499.

doi: 10.3389/fpubh.2021.625499
Objective(s): To estimate the impact of universal community face mask use in Victoria, Australia along with other routine disease control measures in place.

Methods: A mathematical modeling study using an age structured deterministic model for Victoria, was simulated for 123 days between 1 June 2020 and 1 October 2020, incorporating lockdown, contact tracing, and case findings with and without mask use in varied scenarios. The model tested the impact of differing scenarios of the universal use of face masks in Victoria, by timing, varying mask effectiveness, and uptake.

Results: A six-week lockdown with standard control measures, but no masks, would have resulted in a large resurgence by September, following the lifting of restrictions. Mask use can substantially reduce the epidemic size, with a greater impact if at least $50 \%$ of people wear a mask which has an effectiveness of at least $40 \%$. Early mask use averts more cases than mask usage that is only implemented closer to the peak. No mask use, with a 6-week lockdown, results in 67,636 cases and 120 deaths by 1 October 2020 if no further lockdowns are used. If mask use at 70\% uptake commences on 23 July 2020, this is reduced to 7,961 cases and 42 deaths. We estimated community mask effectiveness to be $11 \%$.

Conclusion(s): Lockdown and standard control measures may not have controlled the epidemic in Victoria. Mask use can substantially improve epidemic control if its uptake is higher than $50 \%$ and if moderately effective masks are used. Early mask use should be considered in other states if community transmission is present, as this has a greater effect than later mask wearing mandates.

Keywords: Coronavirus - COVID-19, mask effectiveness, universal masks use, modeling study, outbreak control

\section{SIGNIFICANCE OF THE STUDY}

\section{The Known}

Face masks were mandated in Victoria from 23 July 2020 onward, along with a 6-week stage three lockdown which commenced on 9 July 2020. Masks reduce the risk of infection with beta-coronaviruses.

\section{The New}

Without masks, a 6-week lockdown and the current control measures would likely have resulted in a resurgence in Victoria by September 2020. Masks of modest to good quality with high enough 
usage (at least $50 \%$ of people) can substantially improve epidemic control. Early universal mask use results in a smaller epidemic than late mask use adoption.

\section{The Implications}

The Victorian government's decision to mandate mask use is supported by our research. All efforts should be made to ensure the community have the information and means to obtain or make good quality cloth masks, along with instructions on correct mask use. High levels of mask use are required, and other states with community transmission should consider early adoption of universal facemasks. Masks were estimated to be $11 \%$ effective.

\section{INTRODUCTION}

In late 2019, throughout most of 2020, and prior to the rollout of vaccines, the available control measures for the COVID19 pandemic were limited to non-pharmaceutical interventions (NPIs). NPIs are not enough on their own, and all interventions and measures must be used together to control a pandemic (1). Australia was one of the few countries in the world to achieve suppression of COVID-19, experiencing long periods without local transmission (2). Australia used border closures, travel bans (3), testing, contact tracing, quarantine, social distancing, and selected mask mandates.

The capital of Victoria, Melbourne, is the second largest city in Australia, with a population of 4.9 million. Melbourne experienced a resurgence of COVID-19 from June to August 2020 requiring a prolonged lockdown and a mask mandate. A mandate for masks in public spaces was issued close to the peak of the second wave on 23 July 2020.

A WHO-commissioned review (4) of NPIs against SARS, MERS-CoV, and SARS-CoV-2 showed a reduction in the risk of infection of $96 \%$ for N95 respirators and $67 \%$ for surgical or 12-layered cotton masks (4). However, the efficacy of different types of masks may vary widely. Respiratory protection can vary from respirators and medical masks to low quality cloth face coverings, with different materials and designs influencing their fit and filtering ability $(5,6)$. However, any mask can reduce exposure to aerosols in healthy people and emissions from infected people (7). Randomized clinical trial data for other viruses show protection using both mechanisms (8).

The control of COVID-19 has been challenging because of asymptomatic infection in up to $50 \%$ of all cases (9-12). Even in symptomatically infected people, $44 \%$ of transmission occurs in the $48 \mathrm{~h}$ prior to showing symptoms, and a further proportion on the first day of showing symptoms (13). Given that identifying potentially infectious people may be impossible in the community, universal mask use during periods of high transmission of SARS-CoV-2 may contribute to epidemic control. However, the role of mask use uptake, effectiveness, and the timing is unknown.

\section{Aims}

To estimate the impact of universal community face mask use in Victoria, Australia, by mask use uptake, effectiveness, and timing.

\section{METHODS}

A mathematical model of SARS-CoV-2 transmission was developed for Victoria, with a population of 6.49 million people, with age distributed as per the Australian Bureau of Statistics (14). An age structured deterministic model was used, with compartments for people who are susceptible (non-immune); latent, not infectious; pre-symptomatic, infectious and diagnosed at two levels of infectiousness; pre-symptomatic, infectious and undiagnosed at two levels of infectiousness; symptomatic, undiagnosed; symptomatic, diagnosed; asymptomatic diagnosed and undiagnosed; quarantined contacts; isolated cases; hospitalized; admitted to ICU; and those who recovered or are deceased as a result of COVID-19. The varying levels of infectiousness was parameterized using longitudinal data on viral shedding, which show the peak of infectiousness in the 2 days prior to symptom onset and the first day of symptoms (13). Each of the compartments was divided into 16 age stratified groups each with a 5 year duration, ranging from 0 to 74 years old, plus an additional age group of $75+$ years.

The model was simulated for 123 days starting on 1 June 2020 and lasted until 1 October 2020, and we started the epidemic with nine symptomatic cases reported on 1 June 2020 and two latent infected cases, which was chosen by fitting the modeled incidence of cases to the notification data (2). The rest of the Victorian population was considered susceptible. The force of infection is constructed to incorporate age-distribution and heterogeneity of contacts in different age-groups, so we used a contact matrix specific to Australia (15). We considered the average latent period to be 5.2 days (16), of which the last 2 days before symptom onset were considered to be infectious (13). In the baseline scenario, using published parameters for COVID-19, we assumed that $35 \%$ of cases were asymptomatic (17), and only 30\% of them will be diagnosed when testing asymptomatic people. We assumed transmission could occur from people without symptoms, as this has been documented (18) and is consistent with credible estimates (17). We assumed a heterogeneous distribution of the infectiveness, with $44 \%$ of transmissions occurring in the last 2 days of the pre-symptomatic state (13), 36\% on the first day of symptoms, and $20 \%$ distributed to the following 6 days of symptoms, with a total of 9 days of being in an infectious state.

Upon infection, a susceptible person (S) enters the latent, noninfectious compartment (E), and become infectious after 3.2 days and may be diagnosed $\left(\mathrm{E}^{\mathrm{t}}\right)$ or undiagnosed $\left(\mathrm{E}^{\mathrm{u}}\right)$. We assumed that traced contacts would be quarantined and that this would result in a 50\% reduction in transmissions (19). When latent people become symptomatic, we assumed that the viral load is high the first day $\left(\mathrm{I}^{1}, \mathrm{I}^{2}\right.$ for symptomatic previously untraced and traced; and $\mathrm{A}^{1}$ for people that never develop symptoms) and then decreases to lower infectious levels in the following 6 days $\left(\mathrm{I}^{11}, \mathrm{I}^{22}\right.$, $\mathrm{A}^{2}$, respectively) (13). Symptomatic people will take 1 day to start isolation (Q) if they are identified early (such as through contact tracing or outbreak investigation) or 5 days (if they selfpresent without any active case finding by health authorities), respectively, (20), and in this state, once isolated, we assume no further transmissions. Depending on age-specific hospitalization and ICU required rates, people can be hospitalized $(\mathrm{H})$ or use an ICU bed (ICU), before recovering (R) or before they die (D). We 
used the following differential equations to simulate the epidemic spread of COVID-19 in Victoria.

$$
\begin{aligned}
d S_{i} / d t & =-\left(1-m_{i}\right) * \lambda_{i} * S_{i} \\
d E_{i} / d t & =\left(1-m_{i}\right) * \lambda_{i} * S_{i}-E_{i} / d_{0} \\
d E_{i}^{u} / d t & =(1-\rho) * E_{i} / d_{0}-E_{i}^{u} / d_{1} \\
d E_{i}^{t} / d t & =\rho * E_{i} / d_{0}-E_{i}^{t} / d_{1} \\
d I_{i}^{1} / d t & =(1-g) * E_{i}^{u} / d_{1}-I_{i}^{1} / d \\
d I_{i}^{2} / d t & =(1-g) * E_{i}^{t} / d_{1}-I_{i}^{2} / d \\
d A_{i}^{1} / d t & =g *\left(E_{i}^{u} / d_{1}+E_{i}^{t} / d_{1}\right)-A_{i}^{1} / d \\
d I_{i}^{11} / d t & =I_{i}^{1} / d-\theta * I_{i}^{11} / d_{4}-(1-\theta) * I_{i}^{11} / d_{6} \\
d I_{i}^{22} / d t & =I_{i}^{2} / d-I_{i}^{22} / d \\
d A_{i}^{2} / d t & =(1-a d r) * A_{i}^{1} / d-A_{i}^{2} / d_{6} \\
d Q_{i} / d t & =a d r * A_{i}^{1} / d+I_{i}^{22} / d+\theta * I_{i}^{11} / d_{4}-(1-h) \\
& * Q_{i} / q_{2}-h * Q_{i} / d_{o 1} \\
d H_{i} / d t & =h * Q_{i} / d_{o 1}-(1-i c u) * H_{i} / d h-i c u * H_{i} / d_{o 1} \\
d I C U_{i} / d t & =i c u * H_{i} / d_{o 1}-I C U_{i} / d_{o 1}
\end{aligned}
$$

\begin{tabular}{|c|c|c|c|}
\hline Parameter & Symbol & Value & References \\
\hline Basic reproduction number & Ro & 2.5 & $(17)$ \\
\hline Latent pre symptomatic period & $d_{0}+d_{1}$ & 3.2 not infectious +2 infectious $=5.2$ & $(16)$ \\
\hline Infectious period & $d_{1}+d+d_{6}$ & $\begin{array}{l}2+1+6=9 \text { days of which } 2 \text { presymptomatic, first } \\
\text { day symptomatic with higher transmissions and } \\
\text { following } 6 \text { days symptomatic with lower } \\
\text { transmissions }\end{array}$ & $(13,17,21-24)$ \\
\hline Time to get isolated once symptomatic & $d+d_{4}$ & $1+4=5$ days & $(20)$ \\
\hline Effectiveness of home quarantine & $\mathrm{RO} / 2$ & $50 \%$ reduction in the $\mathrm{RO}$ & $(19)$ \\
\hline Duration of isolation & $q_{2}$ & 20 days & \\
\hline $\begin{array}{l}\text { Reduced transmission rates mask use as a } \\
\text { combination of proportion wearing it by mask } \\
\text { effectiveness }\end{array}$ & $m_{i}$ & $\begin{array}{l}70 \% \text { wearing masks } 67 \% \text { effective is the base case } \\
\text { scenario; we tested values from } 20 \text { to } 90 \% \text { for the } \\
\text { proportion of the population wearing it and mask } \\
\text { effectiveness }\end{array}$ & $(4,13,25)$ \\
\hline Proportion of asymptomatic or very mild infectious & $g$ & $35 \%$ & $(9,17,26)$ \\
\hline Asymptomatic diagnosed rate & $a d r$ & $30 \%$ & \\
\hline $\begin{array}{l}\text { Proportion of contacts identified for home } \\
\text { quarantine }\end{array}$ & $\rho$ & $80 \%$ & $(27)$ \\
\hline $\begin{array}{l}\text { Proportion of symptomatic people that get isolated } \\
\text { after } 5 \text { days }\end{array}$ & $\theta$ & $90 \%$ & $(27)$ \\
\hline $\begin{array}{l}\text { Age-specific case fatality rate (\%) for the } 16 \text { age } \\
\text { groups } \\
\text { For severe hospitalized and ICU admitted people }\end{array}$ & $\begin{array}{l}\mu 1_{i} \\
\mu 2_{i}=2^{*} \mu 1_{i} \\
\mu 3_{i}=3^{*} \mu 1_{i}\end{array}$ & $\begin{array}{l}0,0,0.2,0.2,0.2,0.2,0.2,0.2,0.4,0.4,1.3,1.3 \\
3.6,3.6,8,14.8\end{array}$ & (28) \\
\hline Hospitalization rates & $h$ & $\begin{array}{l}0-4 \text { years old } 0.003 \\
5-19 \text { years old } 0.001 \\
20-49 \text { years old } 0.025 \\
50-64 \text { years old } 0.074 \\
65-74 \text { years old } 0.122 \\
75+\text { years old } 0.165\end{array}$ & (29) \\
\hline ICU rates from hospitalization & $i c u$ & $\begin{array}{l}14.2 \% \text { in the } 54-79 \text { years old and we used the age } \\
\text { specific hospitalization rates to estimate the age } \\
\text { distribution of the ICU rates, we get } 0.0013(0.13 \%) \\
\text { for } 0-19 \text { years old hospitalized } \\
0.0337(3.37 \%) \text { for } 20-49 \text { and } \\
0.142(14.2 \%) \text { for } 50+\end{array}$ & (30) \\
\hline Time in ICU & $d_{01}$ & 5 days & \\
\hline Time in hospital & $d h$ & 15 days & \\
\hline
\end{tabular}

$$
\begin{aligned}
d R_{i} / d t & =\left(1-\mu 1_{i}\right) *(1-\theta) * I_{i}^{11} / d_{6}+A_{i}^{2} / d_{6}+\left(1-\mu 1_{i}\right) \\
& *(1-h) * Q_{i} / q_{2}+\left(1-\mu 2_{i}\right) *(1-i c u) * H_{i} / d h \\
& +\left(1-\mu 3_{i}\right) * I C U_{i} / d_{o 1} \\
d D_{i} / d t & =\mu 1_{i} *(1-\theta) * I_{i}^{11} / d_{6}+\mu 1_{i} *(1-h) * Q_{i} / q_{2} \\
& +\mu 2_{i} *(1-i c u) * H_{i} / d h+\mu 3_{i} * I C U_{i} / d_{o 1}
\end{aligned}
$$

The force of infection is described as

$$
\begin{aligned}
\lambda_{i} & =\sum_{j=1}^{18} \frac{\beta_{1} * c_{i, j} * E_{j}^{u}}{N}+\sum_{j=1}^{18} \frac{\beta_{2} * c_{i, j} * E_{j}^{t}}{N} \\
& +\sum_{j=1}^{18} \frac{\beta_{3} * c_{i, j} *\left(I_{j}^{1}+I_{j}^{2}+A_{j}^{1}\right)}{N} \\
& +\sum_{j=1}^{18} \frac{\beta_{4} * c_{i, j} *\left(I_{j}^{11}+I_{j}^{22}+A_{j}^{2}\right)}{N}
\end{aligned}
$$

Where $\beta_{1}=\frac{0.44 * R 0}{d_{1}}$ for latent undiagnosed contacts, $\beta_{2}=\frac{\beta_{1}}{2}$ for latent diagnosed and home quarantined (50\% reduction in

TABLE 1 | Model parameters. 
$\mathrm{R} 0), \beta_{3}=0.36 * R 0$ for the first day of symptoms and $\beta_{4}=$ $\frac{0.2 * R 0}{d_{6}}$ for the following 6 days of symptoms. $c_{i, j}$ is the agespecific contact matrix adapted from (15) for Australia, and $N$ is the total population. We then added the mask use reduction in transmissions as a combination of the proportion wearing it and mask effectiveness to reduce the force of infection.

The contact matrix projected for Australia (15) shows increased values on the diagonal, therefore the highest contact rates are between people in the same age-group, followed by rates between the youngest children and adults. The lowest contact rates are in those aged over 75 years.

All values for the parameters used are listed in Table $\mathbf{1 .}$

We modeled the effect of the stage three lockdown which started on 9 July 2020, lasting for 6 weeks until 20 of August 2020 (31). This stipulated that people living in "metropolitan

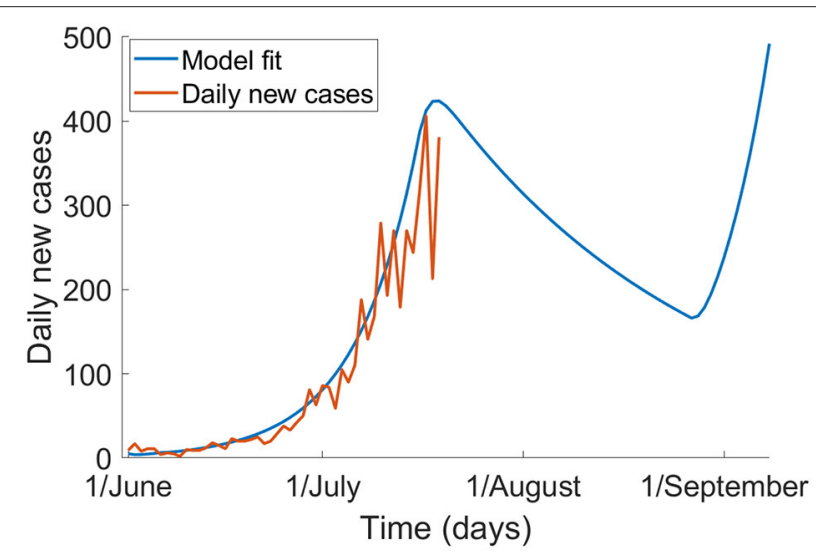

FIGURE 1 | The epidemic of COVID-19 in Victoria without mask use, and with a 6-week lockdown from 9 July to 20 August (blue) and the observed epidemic up to 19 July 2020 based on notification data (red).
Melbourne and the Mitchell Shire you must stay at home. You can only leave home for one of the four reasons-shopping for food and supplies, care and caregiving, exercise, and study and work, if you can't do it from home (31)." We assumed a 50\% reduction in mobility and contact as a result of this, given that not all of Victoria was in lockdown, and people in lockdown are allowed to go to work or to the shops. This is consistent with mobility data from the epidemic in New York City at a similar stage (32). The model assumes that $80 \%$ of all close contacts of diagnosed cases are identified through contact tracing and are quarantined, and $90 \%$ of symptomatic cases are isolated after 5 days (27). These are held as fixed in the model so that the only variation tested is the use of masks. It is necessary to consider these routine disease control interventions, or the size of the epidemic will be unrealistically large. In the base case scenario, we tested medical masks. The effectiveness of wearing medical masks on disease transmission is estimated from a meta-analysis of mask use against beta coronaviruses which found that wearing a medical mask or high-quality cloth mask is $67 \%$ effective in the community setting (4). We conducted a sensitivity analyses on the proportion of people wearing masks (20-90\%) and mask effectiveness in the range of $20-90 \%$ to allow for a range of

TABLE 2 | Cases and deaths in the no-mask scenario compared to starting masks on 1 July or 23 July 2020.

\begin{tabular}{lccl}
\hline $\begin{array}{l}\text { Start wearing } \\
\text { masks }\end{array}$ & $\begin{array}{c}\text { Cases by 1st } \\
\text { of October }\end{array}$ & $\begin{array}{c}\text { Deaths by } \\
\text { the 1st of } \\
\text { October }\end{array}$ & $\begin{array}{l}\text { Reduction in cases } \\
\text { and deaths (\%) }\end{array}$ \\
\hline $\begin{array}{l}\text { No mask and } \\
\text { 6-week lockdown }\end{array}$ & 67,636 & 120 & Base value \\
$\begin{array}{l}\text { 1 July, 70\% } \\
\text { wearing a mask }\end{array}$ & 1,209 & 7 & $-98.2 \%$ in cases \\
23 July, 70\% & 7,961 & 42 & $-94.2 \%$ in deaths \\
wearing a mask & & & $-88.2 \%$ in cases \\
\end{tabular}

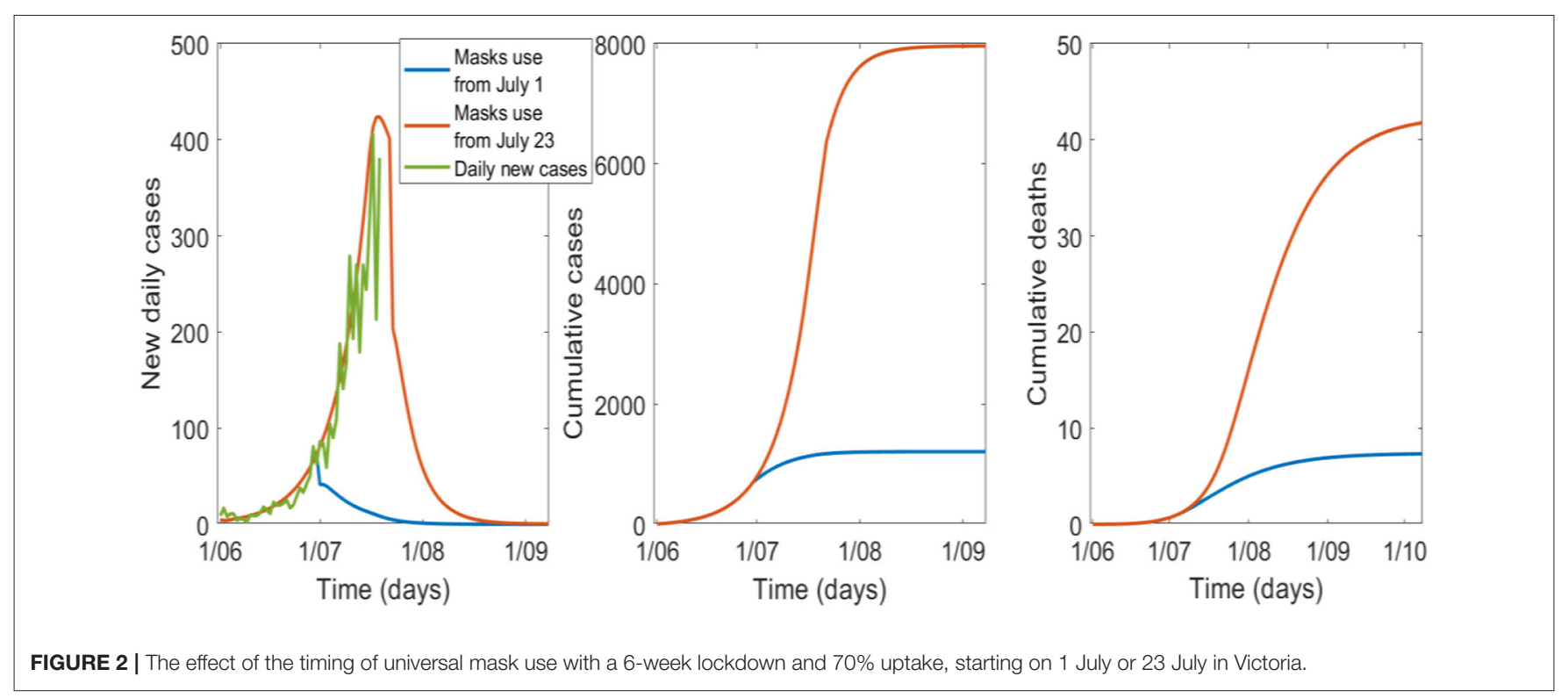


choices from poor quality cloth face coverings to N95 respirators (4). There are no data on cloth masks other than $67 \%$ for 12 layered cloth masks against SARS (4), and no efficacy for a 2layered cloth mask (33). Given the variability of home-made cloth masks, from a scarf to custom-designed masks, we assume a range of effectiveness of $20-67 \%$. This sensitivity analysis also addresses the uncertainty around the baseline case estimate of mask effectiveness. Finally, we used estimates of mask use of $75 \%$ in Victoria (34) and fitted the model to the number of cases observed by 1 October 2020 (35) to estimate the real-world effectiveness of masks during the second wave.

\section{RESULTS}

Figure 1 shows the epidemic without mask use, with the effect of a 6-week stage three lockdown from 9 July until 20 August. The model fits well to data observed from 1 June to 19 July. We show that the epidemic peaks around 19 July and decreases through early to mid-August but will increase again following lifting of the lockdown. With no further outbreak control measures implemented, by 1 October, there may be 67,636 cases and 120 deaths in total.

If universal masks use with a $70 \%$ uptake is added to the 6week lockdown, the epidemic peaks around 19 July and can be controlled by September 2020 (Figure 2, Table 2). If universal masks use started on 1 July, compared to 23 July, it may have reduced cases and deaths from 7,961 to 1,209, and from 42 to 7 , respectively, with a smaller peak in early July.

The sensitivity analysis on the percentage of people wearing masks is shown in Figure 3, Table 3. For good epidemic control, at least $40 \%$ of the population needs to wear good quality masks. If the proportion falls to $20 \%$ (see Table 3 ) the epidemic will result in 14,549 cases and 59 deaths by 1 October.

The sensitivity analysis for efficacy of masks is shown in Figure 4, Table 4 with $70 \%$ of the population wearing masks. Epidemic control is good with masks of effectiveness of $40 \%$ or greater.
Finally, with an estimated $75 \%$ of the population using a mask during the second wave in Victoria (34), the model suggests that the effectiveness of masks was about $11 \%$. With $75 \%$ of people wearing masks of $11 \%$ effectiveness the model shows 20,191 cases by 1 October, which is very close to the 20,183 cases officially reported by the same date (35).

\section{DISCUSSION}

Universal mask use likely contributed to epidemic control during the second wave in Victorian while a 6-week lockdown alone, without mask use, would have resulted in a much larger epidemic and a resurgence by September following the lifting of restrictions. We also show that the effect of masks increases with the increasing uptake and increased effectiveness of the masks. However, even modestly effective masks with uptake levels of $50 \%$ or greater, can substantially improve epidemic control. Masks should be seen as an important measure along with other NPIs during an epidemic of SARS-CoV-2 (1, 4, 36-38).

TABLE 3 | Modeled cases and deaths by 1 October by percentage of the population wearing masks of $67 \%$ efficacy.

\begin{tabular}{lcccc}
\hline People wearing masks (\%) & Cases & $\begin{array}{c}\text { Reduction in } \\
\text { cases (\%) }\end{array}$ & $\begin{array}{c}\text { Deaths } \\
\text { Reduction } \\
\text { in deaths } \\
\text { (\%) }\end{array}$ \\
\hline 0 & 67,636 & Base value & 120 & Base value \\
20 & 14,549 & $-78.5 \%$ & 59 & $-50.8 \%$ \\
30 & 11,091 & $-83.6 \%$ & 52 & $-56.7 \%$ \\
40 & 9,660 & $-85.7 \%$ & 47 & $-60.8 \%$ \\
50 & 8,833 & $-86.9 \%$ & 46 & $-61.7 \%$ \\
60 & 8,341 & $-87.7 \%$ & 44 & $-63.3 \%$ \\
70 & 7,961 & $-88.2 \%$ & 42 & $-65 \%$ \\
80 & 7,656 & $-88.7 \%$ & 41 & $-65.8 \%$ \\
90 & 7,402 & $-89.1 \%$ & 40 & $-66.7 \%$
\end{tabular}
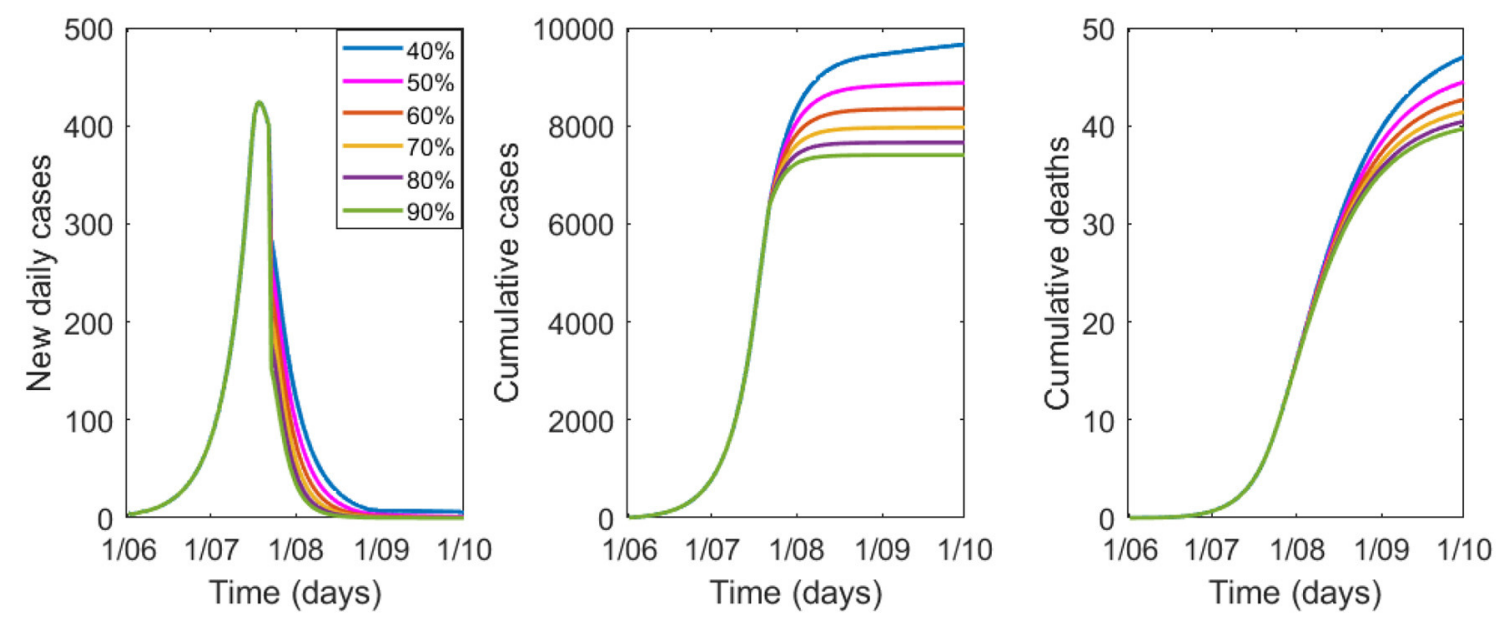

FIGURE 3 | Variation in epidemic control for COVID-19 by percentage of people wearing masks from 40 to $90 \%$, with a mask efficacy of $67 \%$. 

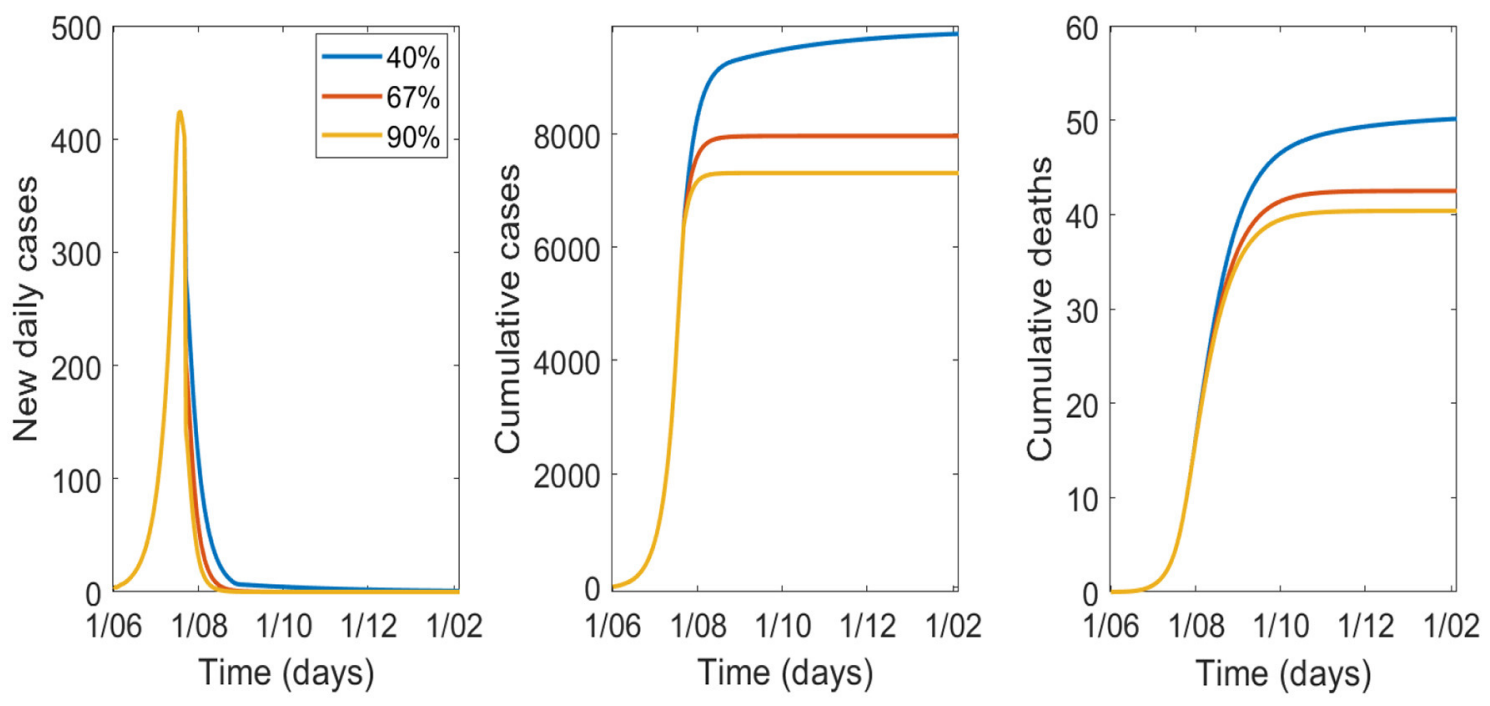

FIGURE 4 | Variation in epidemic control for COVID-19 by varying effectiveness of masks from 40 to $90 \%$, with $70 \%$ wearing a mask.

TABLE 4 | Modeled cases and deaths by 1 October by varying effectiveness of masks and $70 \%$ uptake of masks.

\begin{tabular}{lcccc}
\hline Mask effectiveness \% & Cases & $\begin{array}{c}\text { Reduction in } \\
\text { cases (\%) }\end{array}$ & Deaths & $\begin{array}{c}\text { Reduction } \\
\text { in deaths } \\
\text { (\%) }\end{array}$ \\
\hline 0 & 67,636 & Base value & 120 & Base value \\
20 & 13,916 & $-79.4 \%$ & 58 & $-51.7 \%$ \\
40 & 9,485 & $-86 \%$ & 47 & $-60.8 \%$ \\
67 & 7,965 & $-88.2 \%$ & 42 & $-65 \%$ \\
90 & 7,311 & $-89.2 \%$ & 40 & $-66.7 \%$ \\
\hline
\end{tabular}

We assumed an effectiveness of $67 \%$ of masks in the base case scenario, which requires surgical masks or high-quality cloth masks to be used. The available data on cloth masks suggest a 12layered mask is as effective as a surgical mask (4) but a 2-layered cotton mask may not be very effective (33). By fitting the model to observed cases and knowing the approximate uptake of masks at the time, we estimated that masks were $11 \%$ effective against SARS-COV-2 in Victoria, but that this still markedly reduced cases. The estimated real-world effectiveness of masks in Victoria was low, and likely reflects a wide range of poor-quality masks being used, including single-layered cloth face coverings of poor quality. Notice of the mask mandate was short, and over half of the population used cloth masks, likely home made (34). Cloth masks are the most accessible, feasible, and cost-effective option for the community, and research on improved design of cloth masks has been conducted during the pandemic $(39,40)$. Cloth masks made according to sound design principles, such as at least 3 layers, a water-resistant outer layer, good fit around the face may be as effective as a surgical mask (40). In addition, daily and adequate washing of cloth masks is required for effectiveness (41). Ensuring access to good quality cloth masks, avoiding low quality face coverings such as scarves or bandanas, and providing information on the best methods for making a high-quality mask will enhance protection.

We showed that early, pre-emptive use of facemasks could have prevented much of the epidemic in Victoria. This is challenging in a country where mask use is not a cultural norm, but early mask mandates are an important consideration for any area when experiencing community transmission.

At least $80 \%$ of all COVID-19 infections are mild, especially in younger people, which means that the majority of the burden of infection is at the milder end of the spectrum, as well as asymptomatic infection $(12,42)$. This also means that silent epidemic growth is possible before the scale of the epidemic is apparent. Many infectious people may not be apparent and may not themselves be aware of their infectiousness. The major benefit of mask use in the community is in preventing transmission that may not be easily identified, such as from mild, asymptomatic, or pre-symptomatic cases. Masks may in particular reduce the high risk of transmission in the 2 days prior to symptom onset and the first day of displaying symptoms $(13,18)$.

Masks may work by both protecting healthy people and preventing infected people from onward transmission. Seasonal coronaviruses are exhaled through normal breathing, and the emission of the virus on respiratory aerosols can be blocked completely by a surgical mask (43). In the US, the use of face masks by two infected hairdressers and by all 139 clients whom they serviced while infected, prevented transmission in the hair salon (44). However, one hairdresser did not wear a mask at home and infected household contacts. This provides some real-world evidence of the impact of universal mask use.

Our results are in line with other similar modeling studies. Two modeling studies, one using an SEIR model and a branching model (38), and the other using a next generation matrix model (45), tested mask effectiveness in the population against COVID19. They found that wearing masks significantly reduced the spread, even when poor quality face masks were used, showing 
a very similar range of results, depending on slightly different parameter choices. Another SEIR model (46) has been used to support the same findings, where they showed that even low uptake of masks can have an impact on the epidemic curve. Our model structure is very similar to the one used by Eikenberry et al. (47).

The limitations of this study are the assumptions made for mask effectiveness. If the majority of people use very poor-quality cloth face coverings, the effectiveness would be much lower than the base case assumption of $67 \%$-in fact, the estimation of effectiveness from the study was much lower than $67 \%$. However, the sensitivity analysis of effectiveness estimates, ranging from poor quality cloth masks (20\%) to N95 respirators (90\%), encompasses all scenarios and shows that even low efficacy masks can have an impact on epidemic growth if there is sufficient uptake. We also assumed that the lockdown resulted in a $50 \%$ reduction in social contacts and mobility. If the reduction was greater, the impact of the lockdown would be greater. However, with people allowed to work and shop, schools being partially open and due to some parts of Victoria being exempt, we felt this was a reasonable assumption. A strength of our model is that we used viral shedding data to inform varying infectiousness over time, age-stratified disease parameters, as well as age-specific contact matrices. Some validation of the model was provided by the good model fit to the observed epidemic curve in Victoria.

\section{REFERENCES}

1. Kucharski AJ, Klepac P, Conlan A, Kissler S, Tang M, Fry H, et al. Effectiveness of isolation, testing, contact tracing, and physical distancing on reducing transmission of SARS-CoV-2 in different settings: a mathematical modelling study. Lancet Infect Dis. (2020) 20:1151-60. doi: 10.1101/2020.04.23.20077024

2. Australian Government Department of Health. Coronavirus (COVID-19) Current Situation and Case Numbers. Available online at: https://www. health.gov.au/news/health-alerts/novel-coronavirus-2019-ncov-healthalert/coronavirus-covid-19-current-situation-and-case-numbers (accessed December 8, 2020).

3. Costantino V, Heslop DJ, MacIntyre CR. The effectiveness of full and partial travel bans against COVID-19 spread in Australia for travellers from China during and after the epidemic peak in China. J Travel Med. (2020) 27:taaa081. doi: $10.1093 / \mathrm{jtm} / \mathrm{taaa} 081$

4. Chu DK, Akl E, Duda S, Solo K, Yaacoub S, Schunemann H, et al. Physical distancing, face masks, and eye protection to prevent person-to-person transmission of SARS-CoV-2 and COVID-19: a systematic review and metaanalysis. Lancet. (2020) 395:1973-87. doi: 10.1016/j.jvs.2020.07.040

5. Davies A, Thompson KA, Giri K, Kafatos G, Walker J, Bennett A. Testing the efficacy of homemade masks: would they protect in an influenza pandemic? Disaster Med Public Health Prep. (2013) 7:413-8. doi: 10.1017/dmp.2013.43

6. Rengasamy S, Eimer B, Shaffer RE. Simple respiratory protection-evaluation of the filtration performance of cloth masks and common fabric materials against 20-1000 nm size particles. Ann Occup Hyg. (2010) 54:789-98. doi: 10.1093/annhyg/meq044

7. Van der Sande M, Teunis P, Sabel R. Professional and home-made face masks reduce exposure to respiratory infections among the general population. PLoS ONE. (2008) 3:e2618. doi: 10.1371/journal.pone.0002618

8. MacIntyre CR, Chughtai AA. A rapid systematic review of the efficacy of face masks and respirators against coronaviruses and other respiratory transmissible viruses for the community, healthcare workers and sick patients. Int J Nurs Stud. (2020) 108:103629. doi: 10.1016/j.ijnurstu.2020.103629

9. Mizumoto K, Kagaya K, Zarebski A, Chowell G. Estimating the asymptomatic proportion of coronavirus disease 2019 (COVID-19) cases on board the
Masks are an effective, cheap, low risk addition to other NPIs for the control of SARS-CoV-2 epidemic growth. No single NPI is adequate in controlling COVID-19, but used together, and used early, NPIs including masks can improve epidemic control (48). Pandemic planning could incorporate epidemic thresholds to trigger early mask mandates. Scaling up options for design and supply of good quality cloth masks can improve effectiveness and can be augmented by health promotion and education of community members.

\section{DATA AVAILABILITY STATEMENT}

The original contributions presented in the study are included in the article/supplementary material, further inquiries can be directed to the corresponding author/s.

\section{AUTHOR CONTRIBUTIONS}

CR: ideology, model parametrization, and writing and reviewing. VC: model builder and calibration and writing and reviewing.

\section{FUNDING}

This work was supported by NHMRC, Grant Number: 1137582.

Diamond Princess cruise ship, Yokohama, Japan, 2020. Eurosurveillance. (2020) 25:180. doi: 10.2807/1560-7917.ES.2020.25.10.2000180

10. Byambasuren O, Cardona M, Bell K, Clark J, McLaws M-L, Glasziou P. Estimating the extent of asymptomatic COVID-19 and its potential for community transmission: systematic review and meta-analysis. Off J Assoc Med Microbiol Infect Dis Canada. (2020) 5:223-34. doi: 10.3138/jammi-2020-0030

11. Kimball A, Hatfield KM, Arons M, James A, Taylor J, Spicer K, et al. Asymptomatic and presymptomatic SARS-CoV-2 infections in residents of a long-term care skilled nursing facility - king county, Washington, March 2020. MMWR Morb Mortal Wkly Rep. (2020) 69:377-81. doi: 10.15585/mmwr.mm6913e1

12. Oran DP, Topol EJ. Prevalence of asymptomatic SARS-CoV-2 infection. Ann Intern Med. (2020) 173:362-7. doi: 10.7326/m20-3012

13. He X, Lau E, Wu P, Deng X, Wang J, Hao X, et al. Temporal dynamics in viral shedding and transmissibility of COVID-19. Nat Med. (2020) 26:672-5. doi: 10.1038/s41591-020-0869-5

14. Data by Region. Available online at: https://itt.abs.gov.au/itt/r.jsp? databyregion (accessed February 1, 2021).

15. Prem K, Cook AR, Jit M. Projecting social contact matrices in 152 countries using contact surveys and demographic data. PLoS Comput Biol. (2017) 13:e1005697. doi: 10.1371/journal.pcbi.1005697

16. Li Q, Guan X, Wu P, Wang X, Zhou L, Tong Y, et al. Early transmission dynamics in Wuhan, China, of novel coronavirus-infected pneumonia. $\mathrm{N}$ Engl J Med. (2020) 382:1199-207. doi: 10.1056/NEJMoa2001316

17. CDC. COVID-19 Pandemic Planning Scenarios. Available online at: https://www.cdc.gov/coronavirus/2019-ncov/hcp/planning-scenarios. html. (accessed June 29, 2020).

18. Bai Lingsheng;Wei Tao; Tian Fei; Jin Dong-Yan; Chen,Lijuan; Wang Meiyun YY. Presumed asymptomatic carrier transmission of COVID-19. JAMA Published. (2020) 323:1406-7. doi: 10.1001/jama.2020.2565

19. Zhang S, Diao MY, Yu W, Pei L, Lin Z, Chen D. Estimation of the reproductive number of novel coronavirus (COVID-19) and the probable outbreak size on the Diamond Princess cruise ship: a data-driven analysis. Int J Infect Dis. (2020) 93:201-4. doi: 10.1016/j.ijid.2020.02.033 
20. Wang D, Hu B, Hu C, Zhu F, Liu X, Zhang J, et al. Clinical characteristics of 138 hospitalized patients with 2019 novel coronavirus-infected pneumonia in Wuhan, China. JAMA. (2020) 323:1061-9. doi: 10.1001/jama.2020.1585

21. Lin C, Ding Y, Xie B, Sun Z, Li X, Chen Z, et al. Asymptomatic novel coronavirus pneumonia patient outside wuhan: the value of $\mathrm{CT}$ images in the course of the disease. Clin Imaging. (2020) 63:7-9. doi: 10.1016/j.clinimag.2020.02.008

22. Rothe C, Schunk M, Sothmann P, Bretzel G, Froeschl G, Wallrauch C, et al. Transmission of 2019-nCoV infection from an asymptomatic contact in Germany. N Engl J Med. (2020) 382:970-1. doi: 10.1056/NEJMc2001468

23. Zou L, Ruan F, Huang M, Liang L, Huang H, Hong Z, et al. SARS-CoV-2 viral load in upper respiratory specimens of infected patients. N Engl J Med. (2020) 382:1177-9. doi: 10.1056/NEJMc2001737

24. Du Z, Xu Y, Wu Y, Wang L, Cowling BJ, Mayers LA. Serial interval of COVID-19 among publicly reported confirmed cases. Emerg Infect Dis. (2020) 26:1341-3. doi: 10.1101/2020.02.19.20025452

25. Wang Y, Tian H, Zhang M, Guo D, Wu W, Zhang X, et al. Reduction of secondary transmission of SARS-CoV-2 in households by face mask use, disinfection and social distancing: a cohort study in Beijing, China. BMJ Glob Heal. (2020) 5:e002794. doi: 10.1136/bmjgh-2020-002794

26. Mizumoto K, Chowell G. Transmission potential of the novel coronavirus (COVID-19) onboard the diamond Princess Cruises Ship, 2020. Infect Dis Model. (2020) 5:264-70. doi: 10.1016/j.idm.2020.02.003

27. MacIntyre CR, Costantino V, Kunasekaran MP. Health system capacity in Sydney, Australia in the event of a biological attack with smallpox. PLOS ONE. (2019) 14:e0217704. doi: 10.1371/journal.pone.0217704

28. Team TNCPERE. Vital surveillances: the epidemiological characteristics of an outbreak of 2019 novel coronavirus diseases (COVID-19) - China, 2020. China CDC Wkly. (2020) 2:113-22. doi: 10.46234/ccdcw2020.032

29. Garg S, Kim L, Whitaker M, O'Halloran A, Cummings C, Holstein R, et al. Hospitalization rates and characteristics of patients hospitalized with laboratory-confirmed coronavirus disease 2019 - COVID-NET, 14 States, March 1-30, 2020. MMWR Morb Mortal Wkly Rep. (2020) 69:458-64. doi: $10.15585 / \mathrm{mmwr} . \mathrm{mm} 6915 \mathrm{e} 3$

30. Richardson S, Hirsch JS, Narasimhan M, Crawford JM, McGinn T, Davidson $\mathrm{KW}$, et al. Presenting characteristics, comorbidities, and outcomes among 5700 patients hospitalized with COVID-19 in the New York City Area. JAMA. (2020) 323:2052-9. doi: 10.1001/jama.2020.6775

31. Department of Health and Human Services Victoria. Victorian Healthcare Worker (clinical and non-clinical) coronavirus (COVID-19) Data. Available online at: https://www.dhhs.vic.gov.au/victorian-healthcare-worker-covid19-data (accessed December 16, 2020).

32. Badr HS, Du H, Marshall M, Dong E, Squire MM, Gardner LM. Association between mobility patterns and COVID-19 transmission in the USA: a mathematical modelling study. Lancet Infect Dis. (2020) 20:1247-54. doi: 10.1016/S1473-3099(20)30553-3

33. MacIntyre CR, Seale H, Dung TC, Hien NT, Nga PT, Chugthai AA, et al. A cluster randomised trial of cloth masks compared with medical masks in healthcare workers. BMJ Open. (2015) 5:e006577. doi: 10.1136/bmjopen-2014-006577

34. MacIntyre CR, Nguyen PY, Chughtai AA, Trent M, Gerber B, Steinhofel K, et al. Mask use, risk mitigation behaviours and pandemic fatigue during the COVID-19 pandemic in five cities in Australia, the UK and USA: a crosssectional survey. Int J Infect Dis. (2021). doi: 10.1016/j.ijid.2021.03.056. [Epub ahead of print].

35. Department of Health and Human Services Victoria. Coronavirus Update for Victoria - 01 October 2020. Available online at: https://www.dhhs.vic.gov.au/ coronavirus-update-victoria-01-october-2020. (accessed March 1, 2021).

36. Zamir M, Shah Z, Nadeem F, Memood A, Atrabaiah H, Kumam P. Non pharmaceutical interventions for optimal control of
COVID-19. Comput Methods Programs Biomed. (2020) 196:105642. doi: 10.1016/j.cmpb.2020.105642

37. Srivastav AK, Tiwari PK, Srivastava PK, Ghosh M, Kang Y. A mathematical model for the impacts of face mask, hospitalization and quarantine on the dynamics of COVID-19 in India: Deterministic vs. stochastic. Math Biosci Eng. (2020) 18:182-213. doi: 10.3934/mbe.2021010

38. Stutt ROJH, Retkute R, Bradley M, Gilligan CA, Colvin J. A modelling framework to assess the likely effectiveness of facemasks in combination with 'lock-down' in managing the COVID-19 pandemic. Proc R Soc A Math Phys Eng Sci. (2020) 476:20200376. doi: 10.1098/rspa.2020.0376

39. Zangmeister CD, Radney JG, Vicenzi EP, Weaver JL. Filtration efficiencies of nanoscale aerosol by cloth mask materials used to slow the spread of SARS-CoV-2. ACS Nano. (2020) 14:9188-200. doi: 10.1021/acsnano.0c05025

40. Chughtaita AA, Seale H, MacIntyre CR. Effectiveness of cloth masks for protection against severe acute respiratory syndrome coronavirus 2. Emerg Infect Dis. (2020) 26:e200948. doi: 10.3201/eid2610. 200948

41. MacIntyre CR, Dung TC, Chughtai AA, Seale H, Rahman B. Contamination and washing of cloth masks and risk of infection among hospital health workers in Vietnam: a post hoc analysis of a randomised controlled trial. $B M J$ Open. (2020) 10:e042045. doi: 10.1136/bmjopen-2020-042045

42. Epidemiology Working Group for NCIP Epidemic Response, Chinese Center for Disease Control and Prevention. The epidemiological characteristics of an outbreak of 2019 novel coronavirus diseases (COVID19) in China. Zhonghua Liu Xing Bing Xue Za Zhi. (2020) 41:145-51. doi: 10.3760/cma.j.issn.0254-6450.2020.02.003

43. Leung NHL, Chu DKW, Shiu EWC, Chan KH, McDevitt JJ, Hau BJP, et al. Respiratory virus shedding in exhaled breath and efficacy of face masks. Nat Med. (2020) 26:676-80. doi: 10.1038/s41591-020-0843-2

44. Hendrix MJ, Walde C, Findley K, Trotman R. Absence of apparent transmission of SARS-CoV-2 from two stylists after exposure at a hair salon with a universal face covering policy - springfield, missouri, may 2020. MMWR Morb Mortal Wkly Rep. (2020) 69:930-2. doi: 10.15585/mmwr.mm6928e2

45. Fisman DN, Greer AL, Tuite AR. Bidirectional impact of imperfect mask use on reproduction number of COVID-19: a next generation matrix approach. Infect Dis Model. (2020) 5:405-8. doi: 10.1016/j.idm.2020.06.004

46. Worby CJ, Chang HH. Face mask use in the general population and optimal resource allocation during the COVID-19 pandemic. Nat Commun. (2020) 11:1-9. doi: 10.1038/s41467-020-17922-x

47. Eikenberry SE, Mancuso M, Iboi E, Phan T, Eikenberry K, Kuang Y, et al. To mask or not to mask: modeling the potential for face mask use by the general public to curtail the COVID-19 pandemic. Infect Dis Model. (2020) 5:293-308. doi: 10.1016/j.idm.2020.04.001

48. Ngonghala CN, Iboi E, Eikenberry S, Scotch M, MacIntyre CR, Bonds $\mathrm{MH}$, et al. Mathematical assessment of the impact of non-pharmaceutical interventions on curtailing the 2019 novel Coronavirus. Math Biosci. (2020) 325:108364. doi: 10.1016/j.mbs.2020.108364

Conflict of Interest: The authors declare that the research was conducted in the absence of any commercial or financial relationships that could be construed as a potential conflict of interest.

Copyright $\odot 2021$ Costantino and Raina MacIntyre. This is an open-access article distributed under the terms of the Creative Commons Attribution License (CC BY). The use, distribution or reproduction in other forums is permitted, provided the original author(s) and the copyright owner(s) are credited and that the original publication in this journal is cited, in accordance with accepted academic practice. No use, distribution or reproduction is permitted which does not comply with these terms. 